\title{
Civilisations
}

Revue internationale d'anthropologie et de sciences

humaines

42-2 | 1993

enQuete d'identité

\section{Les caméléons des Balkans}

Irina Nicolau

\section{OpenEdition}

Journals

Édition électronique

URL : http://journals.openedition.org/civilisations/2350

DOI : 10.4000/civilisations.2350

ISSN : 2032-0442

\section{Éditeur}

Institut de sociologie de l'Université Libre de Bruxelles

\section{Édition imprimée}

Date de publication : 1 décembre 1993

Pagination : 175-178

ISBN : 2-87263-108-9

ISSN : 0009-8140

\section{Référence électronique}

Irina Nicolau, «Les caméléons des Balkans », Civilisations [En ligne], 42-2 | 1993, mis en ligne le 01 décembre 1996, consulté le 03 mai 2019. URL : http://journals.openedition.org/civilisations/2350 ; DOI : 10.4000/civilisations.2350

Ce document a été généré automatiquement le 3 mai 2019.

(c) Tous droits réservés 


\title{
Les caméléons des Balkans
}

\author{
Irina Nicolau
}

1 L'ethnologue de nos jours est tenté de négliger une de ses tâches, celle de s'émerveiller. Moi, je crois dans la force cognitive de la stupeur.

2 Les observations qui suivent sont le résultat d'une triple stupéfaction. La première est survenue dans mon enfance et est liée à mon père. La seconde s'est produite il y a quinze ans, quand j'ai lu plusieurs dizaines d'ouvrages sur les Roumains du Sud du Danube. Enfin la troisième je l'ai connue à la même époque, elle a été provoquée par une explication donnée par un Aroumain ${ }^{1}$ âgé, lors d'un entretien.

\section{Premier épisode}

3 Papa était aroumain ; ma mère était grecque. Pendant toute mon enfance j'ai voulu être grecque, je me sentais grecque, mais, quand les frères et les amis de mon père étaient présents, j'étais obligée de me déclarer Aroumaine. Cette duplicité me coûtait beaucoup.

4 Alors, ma stupeur fut grande en découvrant que Papa acceptait d'être considéré comme Grec, ou Bulgare, par les étrangers. Un oncle, aroumain aussi, passait pour Albanais. Pendant les fêtes de famille, tous deux chantaient avec d'autres amis des chansons dans lesquelles ils affirmaient, sur un ton très fanatique, leur identité aroumaine. Les mêmes chansons contenaient des allusions dépréciatives à l'adresse des Grecs, ce qui offensait ma mère, mais personne ne s'en préoccupait. Et dans ces conditions, mon père acceptait, quand cela lui convenait, d'être considéré comme Grec. Cela se manifestait au moment où l' interlocuteur était lui-même grec ou s'il déclarait un penchant pour cette ethnie. Il acceptait d'être nommé bulgare parce que les Bulgares sont considérés chez nous comme des gens peu sophistiqués et très honnêtes. Le caméléonisme de mon père m'intriguait.

Plus tard, j'ai lu dans la monographie sur les Aroumains de Nenitescu que les Roumains des Balkans passent souvent pour des Grecs, des Bulgares, des Serbes et des Albanais, mais que les Grecs, les Bulgares, les Serbes ou les Albanais ne se confondent jamais avec les Aroumains. Le fait d'être polyglotte permettait aux Aroumains d'entretenir cette 
confusion. Mon père lui-même, qui ne parlait bien aucune langue étrangère, détenait des rudiments de toutes les langues balkaniques.

\section{Deuxième épisode}

Durant les années 83-85, j'ai réalisé un recueil d'informations ethnographiques sur les Roumains des Balkans. 150 ans de bibliographie. Ce qui m'a fortement frappé, c'est le grand nombre d'ethnonymes par lesquels les auteurs faisaient référence aux Aroumains. J 'ai dénombré 65 ethnonymes et la liste ne contient pas les noms dérivés de toponymes (comme par exemple Crusoveni - de Crusovo, Verieni de Veria, Molovisteni de Moloviste) ni les sobriquets.

Beaucoup de ces ethnonymes restent obscurs pour moi. Cinq d'entre eux viennent de vlah qui, dans les Balkans, est assimilé au métier de berger. Le même métier, cette fois-ci désigné par le mot turc cioban , a donné aussi un ethnonyme. Deux autres professions, celle de maçon - goga et celle de marchand de chevaux - tîntar, sont devenues à leur tour des ethnonymes. Je n'insiste pas sur ce que pourrait apporter une analyse ethnolinguistique. Je garde ma stupeur initiale. Pourquoi le nombre d'ethnonymes est-il si grand?

\section{Troisième épisode}

Pendant les trois années où j'ai travaillé sur les Aroumains, j'ai fait aussi du terrain en Dobrogea. Lors d'un entretien qui portait sur le problème des noms des Aroumains, un vieillard de 80 ans m'a donné l'explication suivante :

«Les Grecs nous appellent Kutovlahi, les Aroumains de Grèce Vîryareni, les Bulgares Vlasi, les Aroumains Farsirotes Cipani, les Roumains de Roumanie Machedoni. Personne ne sait que nous sommes Gramusteani » .

Comment peut-on vivre cette luxuriante synonymie! C'est comme si ton père t'appelait Jean, ta mère Pierre, tes frères Gabriel, ta femme François, tes amis Marcel et tes ennemis Jacques. Mais il existe des nuances qui méritent d'être présentées : Cutovlah est traduit par les Grecs par une étymologie populaire comme "roumain boiteux », ce qui exprime leur mépris. Les Aroumains de Grèce les appellent Vîryareni, ce qui signifie « de Bulgarie » et c' est une manière de les distinguer des autres groupes aroumains qui vivent dans d'autres pays des Balkans. Les Aroumains Farsirotes les nomment Cipani en faisant une autre distinction qui, cette fois ne vient pas du pays où ils vivent mais d'une particularité vestimentaire. Les Roumains les appellent Machedoni utilisant le terme générique qui s'est imposé à la fin du siècle passé en Roumanie pour les Roumains du sud. Eux-mêmes se nomment Gramusteani, faisant référence à la montagne Gramuste et à la ville Gramoste autour desquelles ils vivaient. Mon informateur et son groupe se reconnaissaient dans ces six ethnonymes.

$11 \mathrm{Au}$ moment où commence l'analyse la stupeur s'affaiblit. Pourtant la stupeur doit continuer à être exploitée en ajoutant que même le vocabulaire technique des historiens, ethnographes, folkloristes et linguistes n'est pas unitaire. Dans leurs descriptions et dans leurs analyses ils sont nommés : Aroumains, Roumains du sud du Danube, Roumains des Balkans, Macédoniens grecs vlahophones. 

d'une tendance plus générale. Utilisant les termes de Gabriel Liiceanu (1981), les Aroumains sont polytropes et haplotropes en même temps. Ulysse et Achille confondus dans la même personne. Les côtés versatiles sont orientés vers l'extérieur (Ulysse même prétend que son nom est Personne pour en tirer profit). Alors, on est versatile envers l' extérieur, envers l'étranger. Achille, quant à lui, est exclusivement orienté vers l'intérieur où les choses sont simples, rigoureuses et claires.

13 Mais il y a un autre paradoxe - du moins je le conçois comme paradoxe - qui vient du fait que tous les Roumains des Balkans ont une seule réponse, celle donnée par Achille, à la question: qui sommes-nous? Le mot employé est Român dans les deux variantes phonétiques dialectales Armân et Ramân .

14 Je finirai en citant Dumitru Staniloae (1987) : «Le fait que je ne peux pas me communiquer intégralement aux autres, découvre ma qualité de mystère inépuisable, mais en tant que mystère, je ne me connais qu'en me communiquant aux autres.»

\section{BIBLIOGRAPHIE}

Liiceanu, G.,1981, Incercare in politropia omului si a culturii, Bucuresti, Cartea Româneasca Scurtu, V., 1942, « Cercetari folclorice in Ugocea româneasca », in : Analele arhivei de Jolclor , Bucuresti, VI, pp. 123-150.

Staniloae, D., 1987, Chipul nemuritor al lui Dumnezeu, Craiova.

\section{NOTES}

1. Note de la Rédaction. En ce qui concerne le terme "Aroumain", voir l'article de Mesnil \& Popova dans ce volume.

\section{RÉSUMÉS}

The Balkan Rumanians call themselves or are called by a great number of ethnonyms. The autor draws attention on the strategies of ethnie dissimulation which these ethnonyms allow for. 
INDEX

Mots-clés : identité, Balkans, Roumanie, ethnicité, appartenance

Keywords : identity, Romania, ethnicity, belonging

\section{AUTEUR}

IRINA NICOLAU

Musée du Paysan Roumain, Bucarest 